\title{
13
}

\section{Toward Osteogenic Differentiation of Marrow Stromal Cells and In Vitro Production of Mineralized Extracellular $\quad 4$ Matrix onto Natural Scaffolds}

Ana M. Martins, Catarina M. Alves, Rui L. Reis, Antonios G. Mikos, 6 and F. Kurtis Kasper

Tissue engineering has emerged as a new interdisciplinary field for the repair of various tissues, 8 restoring their functions by using scaffolds, cells, and/or bioactive factors. A temporary scaf- 9 fold acts as an extracellular matrix (ECM) analog to culture cells and guide the development 10 of new tissue. In this chapter, we discuss the preparation of naturally derived scaffolds of 11 polysaccharide origin, the osteogenic differentiation of mesenchymal stem cells cultured on 12 biomimetic calcium phosphate coatings, and the delivery of biomolecules associated with 13 ECM mineralization.

\section{Abbreviations}

BMP bone morphogenetic protein

$\begin{array}{ll}\text { BMP-2 bone morphogenetic protein-2 } & 17\end{array}$

$\begin{array}{ll}\text { BMSC bone marrow stromal cell } & 18\end{array}$

BMSSC bone marrow stromal stem cell $\quad 19$

$\begin{array}{lr}\mathrm{CaP} & 20\end{array}$

$\begin{array}{ll}\text { ECM extracellular matrix } & 21\end{array}$

$\begin{array}{ll}\text { FGF-1 fibroblast growth factor-1 } & 22\end{array}$

$\begin{array}{ll}\text { FGF-2 fibroblast growth factor-2 } & 23\end{array}$

IGF-2 insulin-like growth factor-2

A. M. Martins, C. M. Alves, and R. L. Reis - 3B's Research Group - Biomaterials, Biodegradables and Biomimetics, University of Minho, Headquarters of the European Institute of Excellence on Tissue Engineering and Regenerative Medicine, AvePark, 4806-909, Taipas, Guimarães, Portugal

IBB - Institute for Biotechnology and Bioengineering, PT Government Associated Laboratory, Guimarães, Portugal A. M. Martins, A. G. Mikos, and F. K. Kasper - Department of Bioengineering, Rice University, 6100 Main Street, Houston, TX 77005-1892, USA

D.A. Puleo and R. Bizios (eds.), Biological Interactions on Materials Surfaces,

DOI 10.1007/978-0-387-98161-1_13, (C) Springer Science+Business Media, LLC 2009 


\section{A. M. Martins et al.}

$\begin{array}{ll}25 & \text { MSC } \\ 26 & \text { RGD } \\ 27 & \text { SBF } \\ 28 & 1.0 \mathrm{SBF} \\ 29 & 1.5 \mathrm{SBF} \\ 30 & \text { SPCL } \\ 31 & \text { TGF- } \beta \\ 32 & \text { TGF- } \beta 1\end{array}$ mesenchymal stem cell

arginine-glycine-aspartic acid

simulated body fluid

simulated body fluid (normal concentration)

concentrated simulated body fluid $(1.5 \times$ normal concentration)

blend of starch and poly( $\varepsilon$-caprolactone $)$

transforming growth factor- $\beta$

transforming growth factor- $\beta 1$

\subsection{Introduction}

Bone is a dynamic, highly vascularized tissue with a unique capacity to heal and remodel without leaving a scar. It is the structural framework of the body and is composed of an inorganic mineral phase of hydroxyapatite and an organic phase of mainly type I collagen. Bone continuously resorbs and reforms in a remodeling process that is carried out by two types of bone cells: the bone-building osteoblasts and the bone-resorbing osteoclasts. Slowly and insidiously, bone deteriorates, losing minerals and structure. Bone injuries produced as a result of disease and/or trauma present a major health concern. A fracture, usually of the hip, wrist, or a vertebra, is often the first indication that osteoporosis has been weakening the bones of a patient for years [1]. Treatment options include transplantation, surgical repair, prostheses, mechanical devices, and drug therapy [2]. However, major damage to a tissue or organ can neither be repaired nor long-term recovery effected in a truly satisfactory way using these methods.

In this context, an emerging field of science termed "tissue engineering," defined as an "interdisciplinary field that applies the principles of engineering and life sciences toward the development of biological substitutes that restore, maintain, or improve tissue function" [3] has been gaining significant recognition. Tissue engineering uses organ-specific cells for seeding a scaffold ex vivo, however it may also involve the implantation of an acellular construct for guided tissue regeneration [4]. Indeed, a wide range of strategies exists for tissue engineering in general, and bone tissue engineering specifically.

Bone tissue engineering is a rapidly expanding field, full of innovative ideas for treating bone trauma and pathologies. Selection of the most appropriate material to produce a scaffold in bone-related applications is a very important step toward the construction of a tissue-engineered construct. There is an increasing interest in the production of novel scaffolds from renewable resources. Natural polymers are an attractive alternative to synthetic polymers for various clinical applications partly due to their biocompatibility and also because they are typically biodegraded by "normal" and/or enzymatic hydrolysis (carried out, in the majority of cases, by specific enzymes also present in the human body). Some of the advantages associated with naturally derived biomaterials are their cost effectiveness as well as the wide range of properties and structures attainable with these materials. A large number of different naturally derived biomaterials have been studied and proposed for bone tissueengineering applications, namely polysaccharides (chitosan, starch, alginate, hyaluronic acid, and cellulose, among others) and proteins (soy, collagen, and fibrin). Polysaccharides, in particular, have some attractive properties, such as nontoxicity (pertinent monomer residues are not hazardous to health), high swelling ability, and stability over a range of $\mathrm{pH}$ values.

For successful bone replacement, the ideal scaffold should be biocompatible [5-8] with the surrounding biological fluids and tissues to avoid any detrimental tissue response. The scaffolding material should degrade into nontoxic residues that can be easily removed from 


\section{Toward Osteogenic Differentiation of Marrow Stromal Cells and In Vitro Production}

the body through normal excretion processes $[5,6,8,9]$. The scaffolds serve as temporary 71 substrates for living cells as well as physical supports for tissue regeneration [10]. Adequate 72 surface area and appropriate surface energy are also needed to permit cell adhesion, promote 73 cell proliferation, and allow retention of differentiated cell functions [5-8, 10]. In addition, 74 sufficient mechanical stability of the scaffold material is necessary to maintain the desired 75 shape and structure during cell culture in vitro and transplantation in vivo. Control of scaffold 76 pore morphology is critical for controlling cell colonization rates and maintaining transport 77 of oxygen, nutrients, and metabolic waste, as well as for supporting organization of the engi- 78 neered tissue. Furthermore, angiogenesis, a requirement for the survival and success of vas- 79 cularized tissues, can be affected by the porosity of the scaffold 1. Pore morphology can also 80 be expected to significantly affect scaffold degradation kinetics and the mechanical proper- 81 ties of the developing tissue $[6,11]$.

The scaffolds used for tissue-engineering purposes mimic the extracellular matrix (ECM) of the regenerating bone environment. Thus, in addition to serving as a mechanical support, a tissue-engineering scaffold may also be "informative" to the cells. An ideal three-dimensional (3D) construct for bone tissue engineering, above all other pertinent characteristics, should be simultaneously osteoinductive (capable of recruiting osteoprogenitor cells and stimulating their differentiation along the bone-forming cell lineage), osteoconductive (capable of supporting the formation of bone at the surface of the scaffold), and also resorbable and amenable to gradual replacement by newly formed bone [12]. In the medical field, consideration of biodegradation is a priority on the list of safety standards when choosing polymers as potential biomaterials for tissue-engineering applications. Naturally derived materials have recently gained interest, as they are structurally similar to the native ECM of many tissues; exhibit excellent biocompatibility; and induce minimal inflammatory response and tissue damage. Natural polymers may present a biologically active environment to the cells, since they usually contain domains that provide cues and can send important signals to guide cells at various stages of development [10].

A method to potentially increase the biological activity of a bone tissue-engineering scaffold is to coat the surface of scaffolds with calcium phosphate $(\mathrm{CaP})$. One of the main goals of using $\mathrm{CaP}$ coatings on bone tissue-engineering scaffolds is to promote osteoconduction by enhancing adhesion of osteogenic cells and ingrowth of bone into porous biomaterials [13]. New technologies have been developed to promote osteogenic activity of bone tissueengineering scaffolds. These approaches tend to integrate into the coatings osteoinductive or bioactive agents (e.g., enzymes and antibiotics), to immobilize constitutional elements of bone (e.g., growth factors, including bone morphogenetic proteins [BMPs] and other members of the transforming growth factor [TGF]- $\beta$ superfamily), adhesion proteins (e.g., collagen, fibronectin, laminin, and vitronectin) and peptides (e.g., the arginine-glycine-aspartic acid [RGD] sequence) on the surface of biomaterials. Immobilization and/or delivery of bioactive molecules at specific sites have been exploited to enhance cell adhesion, differentiation, and other cell functions as well as to promote mineralization of the ECM of the tissueengineered bone constructs.

\subsection{Scaffolds of Natural Origin - Polysaccharides}

A large number of natural polymers, including polysaccharides, have been suggested 113 as candidates for the production of scaffolds for bone tissue-engineering purposes. 114 Polysaccharides are relatively complex carbohydrates. They are high molecular weight poly- 115 mers having one or more monosaccharide repeating-units joined together by glycosidic 116 


\section{A. M. Martins et al.}

117 bonds. Polysaccharides tend to be amorphous and insoluble in water. Some of the main advantages associated with this class of polymers are wide availability, cost effectiveness, good hemocompatibility (probably because of their similarities with heparin), nontoxicity, and a wide range of properties and structures suitable for biomedical applications. These polymers have been proposed as scaffolds for bone tissue-engineering applications as well as carriers for cells and bioactive molecules (e.g., proteins, enzymes, and growth factors) for controlled-release systems.

Chitosan, starch, and alginate, three examples of polysaccharide materials, will be described in detail in the sections that follow.

\subsubsection{Chitosan}

Chitosan, a naturally derived polymer, is a partially deacetylated derivative of chitin found in crustacea exoskeletons (e.g., shrimp, crab, and lobster), cell walls of fungi, and cuticles of insects $[14,15]$. Depending on the source and preparation procedure, the molecular weight of chitosan may range from 300 to more than $1,000 \mathrm{kDa}$ [11]. Chitosan is a suitable AU2 functional biomaterial because it is biocompatible, biodegradable, minimally immunogenic, nontoxic, and hydrophilic. Moreover, it has adsorption properties with remarkable affinity for proteins, and is not expensive [16-21]. Some studies report that chitosan enhanced osteogenesis [22-24] and improved wound healing [25, 26]. In addition, chitosan is a hemostatic agent [11, 16] with antithrombogenic properties [27]. It has proved to be a useful excipient in various drug delivery systems due to its nontoxicity, high cohesiye and hydrophilic properties, and polycationic character resulting from primary amine groups, which provide a high charge density in acidic solutions $(\mathrm{pH}<6.5)[18,28]$. It is soluble in dilute or weak acids (such as acetic and formic acid), but it is normally insoluble in aqueous solutions above $\mathrm{pH} 6.5$.

Chitosan is a binary polyheterosaccharide of $N$-acetylglucosamine and glucosamine with a $\beta 1 \rightarrow 4$ linkage. The superior tissue compatibility of chitosan can be partially attributed to its structural similarity to glycosaminoglycans, which are major components of the ECM of bone and cartilage [15, 29]. Chitosan is easily hydrolyzed by various chitosanases [30], which are completely absent in mammals, and is biodegraded in the presence of lysozyme in aqueous media in vitro [17, 31-35]; this degradation process depends on the degree of deacetylation [31], which represents the proportion of $N$-acetyl-D-glucosamine units with respect to the total number of units [30]. Chitosan degradation kinetics are inversely related to the degree of deacetylation $[31,32]$. In vitro and in vivo, chitosan is degraded by enzymatic hydrolysis; the primary agent of this process is lysozyme, which targets acetylated residues [36]. Chitosan and glucosamine, its biodegradation product, are not toxic in vivo [37]. Lysozyme, or muramidase, is an enzyme that catalyzes the hydrolysis of the peptidoglycan layer of bacterial cell walls [38]. This enzyme is active over a broad $\mathrm{pH}$ range (from 3 to 8) and hydrolyzes its substrates both inside and outside cells. Lysozyme is widely distributed in the human body [39]. It is found in the nose, bronchus, bronchiole, middle ear, lacrimal gland, bone marrow, and digestive tract [16], and in lymphocytes; lysozyme is also secreted by monocytes, macrophages, and granulocytes, which are the largest source of the enzyme $[40,41]$. Monocytes and macrophages are the primary contributors to the lysozyme content in human serum [41]; the concentration in serum is in the range of 7-13 mg/L [39]. The susceptibility of chitosan to degradation induced by lysozyme make the protein an attractive target for incorporation into this biodegradable material [29, 42-44].

Incorporation of active biomolecules, such as growth factors, has been used as a highly beneficial strategy for improving bone regeneration in tissue-engineering applications. The 


\section{Toward Osteogenic Differentiation of Marrow Stromal Cells and In Vitro Production}

biological activity of chitosan on bone regeneration has been confirmed in many studies [18, 45]. 163 Chitosan can be easily fabricated into bulk porous scaffolds, films, microparticles, sponges, 164 and beads. The feasibility of forming porous scaffolds permits wide application of this poly- 165 mer in tissue engineering. This is mainly true for bone tissue-engineering applications 166 because chitosan supports osteoblast proliferation and phenotypic expression [15]. Chitosan 167 fiber meshes with appropriate mechanical properties, developed by Tuzlakoglu et al. [46], 168 exhibited bioactivity; this is a very important aspect for biomaterials used as bone tissue- 169 engineering scaffolds. Martins et al. [35] proposed the development of chitosan-based scaf- 170 folds with the capability of forming porous structures in situ following attack by specific 171 enzymes (namely, $\alpha$-amylase and lysozyme) present in the human body. In addition to the 172 capability of forming pores in situ, other advantages these scaffolds have when compared 173 with other conventional materials are their suitable mechanical properties and lack of toxic- 174 ity. Coutinho et al. [47] studied the function of an osteoblastic-like cell line (SaOs-2) on 175 chitosan blends with synthetic biodegradable polymers, and reported enhanced the osteoblas- 176 tic activity. Costa-Pinto et al. [48] formulated scaffolds based on blends of chitosan and 177 synthetic polyesters, and provided evidence that these scaffolds are cytocompatible. 178 Furthermore, chitosan-based scaffolds promoted the attachment and proliferation of mouse 179 mesenchymal stem cells (MSCs) [48], which exhibited high levels of alkaline phosphatase 180 activity and produced a mineralized ECM [48].

\subsubsection{Starch}

Starch is one of the most abundant naturally occurring polymers with properties that 183 make it attractive for several biomedical applications. Starch is found as insoluble granules 184 of $\alpha$-amylose (20-30\%) and amylopectin (70-80\%) [49]. Amylopectin polymers are highly 185 branched structures containing $(1 \rightarrow 4)-\alpha$-D-glucose and $(1 \rightarrow 6)$ - $\alpha$-D-glucose linkages, 186 whereas amylose is much more linear with long stretches of $(1 \rightarrow 4)$ - $\alpha$-D-glucose-linked 187 monomer units. Starch is extremely difficult to process and is brittle when used without the 188 addition of a plasticizer [49]. Over the years, several other materials have been blended with 189 starch to improve its processability, including several synthetic [50-54] and natural polymers, 190 such as polysaccharides [35, 55] and proteins [56]. Reis and coworkers [35, 57-70] have 191 proposed use of starch-based scaffolds for biomedical applications. Starch exhibits low toxicity 192 [35, 64], biodegradability [35, 70-72], and biocompatibility [73-75], which are excellent 193 characteristics for bone tissue-engineering applications. Compared with other biodegradable 194 polymers available, starch is inexpensive, and above all, reusable. Specific enzymes present 195 in the human body, namely $\alpha$-amylase in the blood plasma, can easily degrade starch. The 196 main enzymes involved in starch degradation are $\alpha$-amylases, $\beta$-amylases, $\alpha$-glucosidases, 197 and other debranching enzymes.

An important consideration of biodegradable materials of natural origin being considered for use in the biomedical field is the host response to the degradation products. Starch degradation products are oligosaccharides that can be metabolized to produce energy. Due to their degradation by $\alpha$-amylases, this constitutes another strategy to control and tailor the degradation of starch-based scaffolds. Martins et al. [35] developed a novel biodegradable matrix based on chitosan and starch, with the capability of forming a porous structure in situ following attack by specific enzymes (namely $\alpha$-amylase and lysozyme) present in the 205 human body. These researchers showed that pore size and distribution in the chitosan matrix 206 is controlled by the location of the "sacrificial" phase (i.e., native starch) that is enzymati- 207 cally degraded [35]. This same study reported an interesting approach for the control of 208 


\section{A. M. Martins et al.}

matrix degradation in situ and consequent pore formation, which could result in scaffolds with mechanical properties appropriate for the initial stage of implantation [35]. Martins et al. [76] also studied the influence of $\alpha$-amylase on the degradation of fiber-mesh scaffolds based on a blend of starch and poly( $\varepsilon$-caprolactone) (SPCL) and demonstrated enhanced scaffold porosity and pore size and decreased average fiber diameter with time. Furthermore, culture of rat marrow stromal cells on SPCL fiber meshes (in medium supplemented with $\alpha$-amylase) resulted in enhanced cell proliferation [76].

\subsubsection{Alginate}

Alginate (alginic acid or algin) is a linear polyuronate containing D-mannuronic acid and L-guluronic acid that is abundant in the cell walls of brown algae. Due to the biocompatibility and gelation of alginate with certain divalent cations, it is widely used for cell immobilization and encapsulation. Alginate is soluble in aqueous solutions at room temperature and forms stable gels in the presence of calcium, barium, and strontium without chemical crosslinking agents [77]; for this reason, the viability and biological activity of entrapped cells and biochemical agents are maintained in alginate gels. As a biomaterial, alginate has a number of advantages including biocompatibility and nonimmunogenicity, which are related to its hydrophilicity $[78,79]$.

Several studies examined alginate sponges as scaffolds for tissue-engineering applications [78] and reported that their structural and morphological properties are appropriate for cell culture and proliferation as well as for neovascularization [78]. Other studies reported that alginate supports synthesis of pertinent ECM components by various cell types, and provides an amenable environment for cell encapsulation, drug delivery, and gene delivery [80]. Alginate also permits cotransplantation of multiple cell types and appropriate growth stimuli to promote, for example, the osteogenic phenotype [81]. Encapsulated bone marrow stromal cells (BMSCs) were studied for the purpose of healing bone defects in orthopedics [82]. Studies with gels containing MSCs and alginate beads loaded with vancomycin (a treatment for bone infections), reported that bone marrow-derived MSCs proliferated and expressed alkaline phosphatase, osteopontin, and collagen 1A1 genes [83]. Cai et al. [84] reported expression of bone-specific ECM markers when they examined the ectopic boneforming ability of BMSCs in combination with scaffolds made from alginate gel and implanted subcutaneously in nude mice for 8 weeks. Moreover, hydrogels such as alginate are effective substrates for both two-dimensional (2D) [85] and 3D [78, 85] cell cultures, indicating the suitability of alginate for tissue-engineering applications.

\subsection{CaP Biomimetic Coatings}

Ideally, tissue-engineering scaffolds should mimic, to the greatest degree possible, the properties of the native target tissue in an effort to promote, direct, and control regeneration of a specific, desired type of tissue. The term "biomimetics" is used to describe a branch of science that seeks to produce such "bioinspired" materials for a variety of applications.

Compared with other biomaterials, CaPs have a unique characteristic for bone mimicry and substitution. Their composition resembles that of bone mineral; most importantly, they can induce a biological response similar to that generated during bone remodeling, which involves resorption and formation of new bone tissue [86]. Osteoclasts are responsible for bone mineral degradation, resulting in bone resorption [86]. During bone resorption, 


\section{Toward Osteogenic Differentiation of Marrow Stromal Cells and In Vitro Production}

the degradation products of $\mathrm{CaP}$ (calcium and phosphate ions) are naturally metabolized but 252 do not cause abnormally increased calcium and phosphate levels in urine, serum, or organs 253 [87]. It should be noted that osteoclasts degrade $\mathrm{CaP}$ in a similar fashion as they degrade 254 natural bone [88-90].

In 1972 Hench et al. [91] showed that "Bioglass" (that is, glass in the $\mathrm{Na}_{2} \mathrm{O}-\mathrm{CaO}-\mathrm{SiO}_{2}-256$ $\mathrm{P}_{2} \mathrm{O}_{5}$ system), spontaneously bonded to living bone without formation of surrounding fibrous 257 tissue. In the early 1990s, Kokubo and coworkers [92, 93] proposed that the essential require- 258 ment for a biomaterial to bond to living bone is the formation of bone-like apatite on the 259 surface of the biomaterial when implanted in vivo. This in vivo apatite formation can be 260 reproduced in vitro using simulated body fluid, which is a solution containing inorganic ion 261 concentrations similar to those of human extracellular fluids but without any cells or proteins 262 [94]. Under such in vitro conditions, the formed layer consists of carbonate apatite with small 263 crystallites and low crystallinity [94]. This apatite is referred to as "bone-like apatite" due to 264 its similarity to apatite present in natural bone.

Biomimetic methodology for coating biomaterials with a bone-like apatite layer has 266 been described in several publications [92, 95-98]. This technique mimics the natural 267 biomineralization processes, which involve controlled crystal phase nucleation and growth. 268 The main advantage of the biomimetic methodology is the use of physiological conditions 269 $\left(\mathrm{pH} 7.4\right.$ at $37^{\circ} \mathrm{C}$ ) simulating the conditions under which apatite is formed in bone. 270 Moreover, this technique allows incorporation of proteins and bioactive agents into $\mathrm{CaP} 271$ coatings without compromising bioactivity of the organic compounds [96, 98-101]. In 272 1997, Reis et al. [95] adapted the methodology developed by Kokubo and used bioactive 273 glass as a precursor to nucleation and growth of CaP films on starch-based polymers. 274 Briefly, for the preparation of biomimetic CaP coatings based on the methodology previ- 275 ously developed by Abe et al. [92] and Kokubo [93] and adapted by Reis et al. [95], the 276 materials under consideration were first impregnated with bioactive glass, and were then 277 immersed in simulated body fluid (1.0 SBF) solution for several days at $37^{\circ} \mathrm{C}$; this phase 278 is known as the "nucleation stage" and allows formation of CaP nuclei. In order to acceler- 279 ate apatite formation, the biomaterials were subsequently immersed at $37^{\circ} \mathrm{C}$ in simulated 280 body fluid solution (1.5 SBF) with an ionic concentration 1.5-fold greater than physiologi- 281 cal levels; this condition enhances $\mathrm{CaP}$ nuclei growth. The CaP biomimetic coatings, 282 which are thus formed, exhibit osteoconductive properties that will be discussed later 283 on in this chapter.

\subsubsection{Osteoconductivity}

Scaffolds for bone tissue engineering should be osteoconductive; that is, able to support 286 formation of bone within and/or upon the scaffold. Osteoconductivity has been observed 287 when porous structures were implanted into or adjacent to bone. In such cases, osteoprogeni- 288 tor cells migrated into pores and filled the porous structure with newly formed bone. This 289 process is characterized by an initial ingrowth of fibrovascular tissue that invades the porous 290 structure followed by later development of new bone directly within it [102]. Hydroxyapatite- 291 based materials are osteoconductive, provided that fully differentiated osteogenic cells are 292 available at the site of implantation [12]. Adsorption of growth factors from the local milieu 293 and from the blood circulation contributes to the osteoconductivity of hydroxyapatite by 294 creating suitable conditions for bone formation when implanted in an osseous environment 295 in vivo. Many relatively insoluble CaP materials are osteoconductive, and, in some cases, 296 may induce extraskeletal new bone formation (i.e., they are osteoinductive). 


\section{A. M. Martins et al.}

\subsubsection{Osteoinductivity}

Osteoinduction is the process by which stem and osteoprogenitor cells are recruited to the bone-healing site and stimulated to undergo osteogenic differentiation [103]. Osteoinductivity implies the ability of chemical compounds to induce osteogenic differentiation of uncommitted progenitor cells [12]. It has been proposed that biomaterials do not have an osteoinductive character in the absence of appropriate osteoinductive agents, such as certain BMPs and other bioactive molecules [104]. However, several studies have reported that some CaP biomaterials [105-107], namely CaP coatings [107, 108], may be osteoinductive. These CaP biomaterials may induce bone formation at extraskeletal sites without addition of osteogenic cells or bioactive agents. Hydroxyapatite is not osteoinductive because it cannot induce osteogenic differentiation of progenitor cells when implanted in a nonosseous environment, such as skin and muscle [12].

\subsubsection{Incorporation of Biomolecules into CaP Biomimetic Coatings}

Numerous attempts have been made to improve the osteoconductivity of biomaterials. Coatings of $\mathrm{CaP}$ expedite osteoconduction and bone ingrowth at the surface of bone substitutes and, therefore, are useful strategies in tissue-engineering endeavors for the regeneration of bone tissue. However, a methodology that enables regeneration of bone tissue should not only expedite osteoconduction, but also osteoinduction through biochemical pathways [109-112]. It is known that BMPs can be incorporated into CaP implants (with adequate 3D geometry) to promote osteogenesis $[112,113]$; the surface of such implants, however, will be rapidly conditioned by several highly concentrated molecules [114]. For this reason, other types of delivery-specific approaches have been investigated as alternatives that further functionalize and enhance the potential of CaP coatings. Specifically, the CaP biomimetic coatings have been used as a carrier of various molecules, including osteoinductive agents such as BMPs [115-117], other proteins [101, 118-120], enzymes [96, 98, 101], and antibiotics [13, 121].

Biomimetic $\mathrm{CaP}$ coatings, produced as described in earlier parts of this chapter, are deposited onto surfaces under physiological temperature and $\mathrm{pH}$ [110], enabling coprecipitation and consequent incorporation of biologically active molecules [99]. This approach circumvents difficulties common to plasma spraying techniques. By using low temperatures, biomimetic processes can be applied not only to highly resistant materials (e.g., metallic alloys) but also to polymeric and naturally derived materials (e.g., chitosan, starch, and collagen) for implantation [122].

The major objective of CaP coatings is to provide appropriate biological composition and to improve the quality of the surfaces of various materials used for orthopedic applications. The conditions under which such a coating is prepared affect conformational stability of incorporated biomolecules, and thus the bioactivity and shelf-life of the final product. Such coatings, which are structurally and chemically comparable to the mineral component of bone, can possesses favorable bioactive properties that may facilitate outcomes in cases of critical clinical need $[13,123]$.

This alternative coating technique may be used to produce systems with several advantages, such as reduction of burst release of incorporated molecules into the biological milieu. In this case, biomolecules incorporated in the inorganic phase are gradually released as the latticework undergoes degradation. The advent of the slow degradation of the coating modulates delivery of bioactive agents. Slow release of these chemical compounds may improve the osteoinductive capacity of the implant material [100, 124]. 
One of the potential applications of CaP coatings pertains to the incorporation of bioactive 343 agents and proteins. Azevedo et al. [101] used a biomimetic technique and successfully 344 incorporated bovine serum albumin and $\alpha$-amylase into a CaP coating on the surface of a 345 starch-based polymer. In that study, the properties of the resultant biomaterial were tailored 346 by judicious choice of specific enzymes and their incorporation at different compositions and 347 combinations into CaP coatings that retained their bioactivity [101]. Efficient incorporation 348 of active $\alpha$-amylase into biomimetic coatings controlled the degradation rate of starch-based 349 biomaterials. Similar results and applications were achieved with chitosan scaffolds after 350 incorporation of lysozyme [96, 98]. Martins et al. [96, 98] incorporated lysozyme into CaP 351 coatings on the surface of chitosan scaffolds in order to control the degradation rate of chi- 352 tosan and subsequent formation of pores. Furthermore, since lysozyme has antibacterial 353 properties, these coatings may be used as a carrier for its sustained release, potentially miti- 354 gating infection at the implantation site. Several studies reported in the literature addressed 355 incorporation of BMPs into biomimetic CaP layers [110, 116, 123, 125]. These studies indi- 356 cated that $\mathrm{CaP}$ coatings have the potential for sustained delivery of many other bioactive 357 agents. Liu and coworkers [99] demonstrated that BMP-2 retained its osteoinductivity when 358 delivered from biomimetic systems and that the osteoconductivity of implant material sur- 359 faces was affected by BMP-2 and its delivery mode [123]. 360

In summary, the results discussed in this section support the strategy of adding osteoin- 361 ductive signaling molecules into CaP biomimetic coatings for the purpose of inducing bone 362 growth.

\subsection{Osteogenic Differentiation of Marrow Stromal Cells and Mineralized ECM Production In Vitro}

Biomaterials and scaffolds considered for bone tissue engineering are often evaluated 366 in vitro for their ability to support adhesion, proliferation, and differentiation of progenitor 367 cells along the osteogenic pathway prior to being evaluated in vivo. In vitro cell-scaffold 368 interactions are determined using osteoblasts, osteosarcoma cell lines, and osteoprogenitor 369 cells. The scaffolds used for this purpose mimic the ECM of bone and play a crucial role in 370 supporting cell functions and differentiation, but may also be used to deliver biomolecules. 371

Osteoblastic differentiation of MSCs comprises cell proliferation, cell maturation, and 372 matrix mineralization. During these phases, cells synthesize and secrete alkaline phosphatase, 373 type I collagen, and other noncollagenous ECM proteins, such as osteocalcin, osteopontin, 374 osteonectin, and bone sialoprotein. Mineralization occurs through accumulation of calcium 375 and phosphorous in the ECM.

\subsubsection{BMSCs Versus MSCs}

The osteoprogenitor cells used for bone tissue-engineering purposes are derived from 378 various tissue sources. Bone marrow stroma consists of a heterogeneous cell population that 379 provides structural and physiological support for hematopoietic cells [126]. Bone marrow 380 contains three main cell types: endothelial cells, hematopoietic cells, and stromal cells. 381 Friedenstein $[127,128]$ were the first to identify in bone marrow cell populations with strong 382 osteogenic potential. When marrow cells are plated at low cell densities, BMSCs form colonies 383 known as "colony-forming unit-fibroblasts"; this term indicates that each colony derives from 384 


\section{A. M. Martins et al.}

a single proliferating progenitor [129]. The term "BMSCs" is applied to isolated bone marrow cells with potential to form connective tissues [129].

Due to their high proliferation potential, BMSCs can be expanded in culture to obtain large numbers of cells starting from a small sample of bone marrow aspirate. The BMSC population contains precursor cells capable of extensive proliferation and differentiation into several phenotypes. Furthermore, BMSCs maintain their multipotential capacity during prolonged culture and multiple passages in vitro. Among these BMSCs there is a subpopulation of undifferentiated multipotent cells able to generate "mesenchyme," the mass of tissue that develops from the mesoderm of an embryo. This cell population is present in all postnatal tissues and is referred to as "MSCs" $[130,131]$. In the past, researchers working with cells from the bone marrow used different names to refer to the same cells. This practice lead to nomenclature confusion; for example, BMSCs have been referred to as multipotent adult progenitor cells, MSCs, bone marrow stromal stem cells (BMSSCs), and mesodermal progenitor cells [132]. What is presently known is that, if appropriately induced, these cells can also differentiate along pathways different from those associated with the cells' tissues of origin [133].

Stem cells are able to provide replacements for various differentiated cell types. The use of MSCs has several advantages, as they have unique biological properties, are capable of extensive replication in culture in an undifferentiated state, and can differentiate along multiple pathways to form various cells from a number of tissues, including bone, cartilage, and fat [4]. Identification of stem cells using surface markers has not been definitive either, because similar markers are also present on nonstem cells, or because a particular marker may only be temporarily expressed on a stem cell at a certain stage or under specific conditions.

\subsubsection{Osteogenic Differentiation}

In addition to being osteoconductive and osteoinductive, an ideal scaffold should also be osteogenic (that is, containing living cells capable of differentiation into osteoblasts). Differentiation of MSCs along the osteoblastic lineage in vitro starts with a period of cell proliferation followed by synthesis and deposition of ECM components by the cells; accumulation of calcium finally leads to mineralization of the ECM. To induce osteogenic differentiation in MSCs, the culture medium is usually supplemented with osteogenic agents such as dexamethasone, $\beta$-glycerophosphate, and ascorbic acid.

Dexamethasone, a synthetic glucocorticoid, stimulates MSC proliferation and supports osteogenic lineage differentiation [134-136]. Organic phosphates, such as $\beta$-glycerophosphate, also support osteogenesis by contributing to mineralization of the ECM and modulating osteoblast function [136-138]. Free phosphates can also induce expression of osteogenic protein markers, such as osteopontin $[136,139]$. Other supplements, such as ascorbic acid, enhance collagen synthesis and upregulate alkaline phosphatase expression in bone cells. Ascorbic acid stimulates marrow stromal cells to differentiate along the osteoblast lineage [139-141]. Furthermore, ascorbic acid promotes osteogenic induction evidenced by increased alkaline phosphatase activity and production of osteocalcin in osteogenic cultures [142].

Martins et al. [76] used marrow stromal cells cultured on starch-poly( $\varepsilon$-caprolactone) blend scaffolds in static cultures and reported that the enzyme lipase enhanced osteogenic differentiation and promoted deposition of a mineralized ECM. The BMP family of growth factors is frequently used for osteoinduction. BMP-2 increases calcium-containing nodule formation and the calcium content of osteogenic cultures in vitro [136]. The TGF- $\beta$ superfamily contains a large number of growth factors with different functions, many of which regulate cell proliferation and ECM production. Fibroblast growth factors (FGFs), namely 


\section{Toward Osteogenic Differentiation of Marrow Stromal Cells and In Vitro Production}

FGF-1 and FGF-2, are produced by oseoblasts and are constituents of the bone matrix s. 431 Insulin-like growth factors (IGF) stimulate osteogenesis; IGF-2 is the most abundant growth 432 factor found in bone matrix. Gomes et al. [143] demonstrated that an in vitro generated bone- 433 like ECM produced by marrow stromal cells contains bioactive growth factors including 434 TGF- $\beta 1$, FGF-2, vascular endothelial growth factor, and BMP-2. Pham et al. [144] reported 435 that the gene expression profiles of various bone-related growth factors and ECM proteins in 436 MSCs cultured in osteogenic media were upregulated; these chemical compounds are present 437 in native bone tissue. Costa-Pinto et al. [48] studied the osteogenic differentiation of a mouse 438 MSC line (BMC9) cultured on novel melt-based chitosan/polyester scaffolds and reported 439 high levels of alkaline phosphatase activity and formation of a calcified ECM; these results 440 are evidence of differentiation of the cells along the osteogenic pathway.

Expression of osteoblast phenotype markers in culture defines three different phases of 442 bone-related activities: cell proliferation, ECM maturation, and ECM mineralization. During 443 active cell proliferation, growth-related genes are expressed, and minimal levels of type I col- 444 lagen are observed [145]. Following this phase, a period of matrix maturation occurs when 445 alkaline phosphatase is maximally expressed. Finally, the ECM becomes mineralized, the 446 third period of the bone developmental sequence [145]. There are two transition periods 447 between the aforementioned developmental periods: the first occurs at the end of proliferative 448 period and the second when expression of osteoblastic phenotype markers (such as osteocalcin 449 and osteopontin), become significantly elevated with the onset of mineralization [145]. $\quad 450$

Alkaline phosphatase activity, an early marker of the osteoblastic phenotype, is upregu- 451 lated at the onset of cell differentiation but subsequently decreases as cell differentiation 452 progresses. Another marker of bone formation is calcium-containing mineral deposits in the 453 ECM. To detect mineral deposition, tetracycline- $\mathrm{HCl}$, a fluorochrome-labeling agent for bone 454 tissues [146], is added to the osteogenic culture media [147]. Tetracycline accumulates at sites 455 of bone formation and fluoresces brightly when activated with appropriate fluorescent light. 456 Qualitative (or semiquantitative) analysis of calcium-containing mineral deposits in bone cell 457 cultures uses the von Kossa, alizarin red, and methylene blue/basic fuchsin staining methods 458 [147, 148]. An important artifact, which should be kept in mind when using these analyses, is 459 that the ECM uptakes calcium independently from cell-mediated mineral deposition. For this 460 reason, confirmation of the results obtained using the aforementioned staining methods should 461 be complemented with data from either diffraction or spectroscopy methods such as thin-film 462 X-ray diffraction and Fourier-transformed infrared spectroscopy [76, 148, 149]. 463

Expression of osteopontin occurs during the mid- to late-stages of osteogenic differen- 464 tiation of MSCs [150]. Osteopontin is an extracellular protein secreted by differentiating 465 osteoblasts that is upregulated both during cell proliferation and at the onset of ECM minerali- 466 zation. Osteocalcin, another late-stage marker of osteoblastic differentiation, can be assessed 467 using commercially available immunoassays. Immunohistochemistry using specific antibodies 468 to detect the presence of growth factors, bone- and ECM-related proteins, and enzymes is well 469 established and widely used. Real-time reverse transcriptase polymerase chain reaction is 470 used to determine expression of bone-related genes, such as osteoblast marker genes, growth 471 factors, and ECM biomolecules, in MSCs [144].

\subsubsection{Bone-Specific Matrix Proteins}

The bone matrix is not only composed of a mineralized phase, but also of an organic 474 phase containing collagenous and noncollagenous proteins, matrix metalloproteinases, pro- 475 teoglycans, and glycoproteins. Bone formation involves regulated secretion, deposition, and 476 


\section{A. M. Martins et al.}

removal of a complex array of these matrix proteins, which appear in a defined temporal and spatial sequence [12]. Mineralization also dictates the spatial orientation of matrix deposition [12]. Most proteins originally thought to be unique to the bone ECM were subsequently proven to be expressed in many other tissues of the body. Osteocalcin is the only protein still considered to be bone specific in bone mineralization [12].

As discussed previously, alkaline phosphatase is considered an early-stage marker of osteoblastic differentiation [145] and is expressed during the postcell proliferative period of ECM deposition. Type I collagen, the major ECM protein of bone, provides a template for subsequent mineralization [151]. Alkaline phosphatase, collagen, and osteonectin are expressed at high levels near the end of cell proliferation and during the period of ECM deposition and maturation [139].

Osteopontin and bone sialoprotein, $N$-linked glycoproteins containing integrin-binding RGD motifs, are involved in cell-matrix interactions. Osteopontin is widely distributed in different tissues, whereas bone sialoprotein is highly enriched in bone and skeletal cartilage [152]. Osteopontin, a phosphorylated glycoprotein associated with the early stages of osteogenesis that precede mineralization, is secreted by osteoblasts into the mineralizing ECM during bone development $[139,153]$. In bone, bone sialoprotein is expressed by fully mature osteogenic cells capable of depositing mineralized matrix [152]. Extracellular bone sialoprotein localizes to newly formed, mineralized bone matrix; its distribution coincides with that of mineral deposits [154]. Bone sialoprotein, a protein expressed during the early phases of bone deposition, controls both mineral formation and cell-matrix interactions [155]. This protein is used as a marker of initial bone formation [155]. The function of bone sialoprotein in bone, which has not been completely elucidated yet, may be related to the regulation of physiological mineralization of skeletal ECMs $[154,156]$. Osteocalcin is another marker of late-term osteogenic differentiation associated with osteoblast-mediated matrix deposition and mineralization $[157,158]$. Expression of osteopontin, osteocalcin, and bone sialoprotein occurs later during the third period of ECM mineralization.

\subsection{Summary}

Surface modification of biomaterials uses methods that mimic biomineralization and enable incorporation of bioactive molecules and agents; such treatments can improve both in vitro and in vivo osteogenic differentiation. The main objective of $\mathrm{CaP}$ coatings is osteoconduction and enhanced adhesion of osteogenic cells onto biomaterial surfaces. Because $\mathrm{CaP}$ coatings have structures and chemical properties similar to those of native bone, they have great potential and promise to increase bone ingrowth in areas of clinical need.

Because they lack essential properties, such as bioactivity and osteoinductivity, most currently available polymers present limitations for bone-related biomedical applications. In this respect then, the biomimetic coating technique discussed in the present chapter has the potential to impart these essential properties to biomaterials. Since CaP layers can be applied on 3D scaffolds, the biomimetic-coating approach has been receiving increased attention in the bone tissue-engineering field.

Moreover, CaP coatings have been considered as a potential carrier for the delivery of various biomolecules, chosen for their physicochemical and biological properties as well as for their osteoconductivity. Complementing the CaP biomimetic coating approach, incorporation of biomolecules provides osteoinductive properties to biomaterials. Since this method is carried out under physiological conditions, proteins, enzymes, and other bioactive agents 


\section{Toward Osteogenic Differentiation of Marrow Stromal Cells and In Vitro Production}

can be incorporated into CaP layers without loss of their bioactivity. A major advantage is 522 the fact that the biomaterial-CaP coating-biomolecule can simultaneously exhibit osteoin- 523 ductive and osteoconductive properties, because it can act as a carrier system for the control- 524 led release of multiple biologically active proteins. Incorporation of enzymes into CaP layers 525 coated on the surface of scaffolds (using the biomimetic-coating technique) can be also used 526 to control the degradation rate of the material substrate in vivo. An integrated approach com- 527 bining a material scaffold, CaP coatings, bioactive molecules and/or enzymes, and in vitro 528 cell cultures may provide an optimal environment for cell adhesion and osteogenic differen- 529 tiation as well as generate a mineralized ECM containing select bioactive molecules. $\quad 530$

Incorporation of bioactive molecules into $\mathrm{CaP}$ coatings on scaffolds for tissue-engi- 531 neering applications has the potential to provide advanced, tissue-specific constructs to pro- 532 mote improved alternative treatment of bone pathologies and trauma. The present chapter 533 summarized the results of studies that used biomolecules important to bone tissue engineer- 534 ing. Further research is needed to elucidate important aspects such as details of the release 535 profiles of entrapped bioactive molecules, retention of their bioactivity, etc. Establishment 536 and further development of nature-inspired techniques to design and formulate novel bioma- 537 terials could provide the next generation of effective scaffolds for bone tissue engineering. 538

\section{Acknowledgments}

The authors would like to acknowledge European NoE EXPERTISSUES (NMP3- 540 CT-2004-500283) (R.L.R), Project HIPPOCRATES (NMP3-CT-2003-505758) (R.L.R), and 541 grants from the US National Institutes of Health to A.G.M. (R01 AR42639, R01 DE15164 542 and R01 DE17441).

\section{References}

1. Marx J. Coming to grips with bone loss. Science. 2004;305(5689):1420-1422. 545

2. Persidis A. Tissue engineering. Nature Biotechnology. 1999;17(5):508-510. 546

3. Langer R, Vacanti JP. Tissue engineering. Science. 1993;260(5110):920-926. 547

4. Bianco P, Robey PG. Stem cells in tissue engineering. Nature. 2001;414(6859):118-121. 548

5. Hutmacher DW. Scaffolds in tissue engineering bone and cartilage. Biomaterials. 2000;21(24):2529-2543. 549

6. Salgado AJ, Coutinho OP, Reis RL. Bone tissue engineering: state of the art and future trends. Macromolecular 550 Bioscience. 2004;4(8):743-765. 551

7. Atala A. Engineering tissues, organs and cells. Journal of Tissue Engineering and Regenerative Medicine. 552 2007;1(2):83-96.

8. Hutmacher DW, Schantz JT, Lam CX, Tan KC, Lim TC. State of the art and future directions of scaffold-based 554 bone engineering from a biomaterials perspective. Journal of Tissue Engineering and Regenerative Medicine. 555 2007;1(4):245-260.

9. Langer R, Peppas NA. Advances in biomaterials, drug delivery, and bionanotechnology. AIChE Journal. 557 2003;49(12):2990-3006.

10. Langer R. Selected advances in drug delivery and tissue engineering. Journal of Controlled Release. 1999;62(1- 559 2):7-11.

11. Madihally SV, Matthew HW. Porous chitosan scaffolds for tissue engineering. Biomaterials 561 1999;20(12):1133-1142.

12. Riminucci M Bianco P. Building bone tissue: matrices and scaffolds in physiology and biotechnology Brazilian 563 Journal of Medical and Biological Research = Revista brasileira de pesquisas medicas e biologicas/Sociedade 564 Brasileira de Biofisica et al. 2003;36(8):1027-1036.

13. Daculsi G, Laboux O, Le Geros R. Outcome and perspectives in bioactive coatings: what's new, what's coming. 566 ITBM-RBM. 2002;23:317-325. 


\section{A. M. Martins et al.}

14. Suh JK, Matthew HW. Application of chitosan-based polysaccharide biomaterials in cartilage tissue engineering: a review. Biomaterials. 2000;21(24):2589-2598.

15. Lahiji A, Sohrabi A, Hungerford DS, Frondoza CG. Chitosan supports the expression of extracellular matrix proteins in human osteoblasts and chondrocytes. Journal of Biomedical Materials Research. 2000;51(4):586-595.

16. Muzzarelli RAA. Biochemical significance of exogenous chitins and chitosans in animals and patients. Carbohydrate Polymers. 1993;20(1):7-16.

17. Tomihata K, Ikada Y. In vitro and in vivo degradation of films of chitin and its deacetylated derivatives. Biomaterials. 1997;18(7):567-575.

18. Kumar MNVR. A review of chitin and chitosan applications. Reactive \& Functional Polymers. 2000;46(1):1-27.

19. Benesch J, Tengvall P. Blood protein adsorption onto chitosan. Biomaterials. 2002;23(12):2561-2568.

20. Krajewska B. Application of chitin- and chitosan-based materials for enzyme immobilizations: a review. Enzyme and Microbial Technology. 2004;35(2-3):126-139.

21. Kim IY, Seo SJ, Moon HS, Yoo MK, Park IY, Kim BC, et al. Chitosan and its derivatives for tissue engineering applications. Biotechnology Advances. 2008;26(1):1-21.

22. Klokkevold PR, Vandemark L, Kenney EB, Bernard GW. Osteogenesis enhanced by chitosan (poly-N-acetyl glucosaminoglycan) in vitro. Journal of Periodontology. 1996;67(11):1170-1175.

23. Pound JC, Green DW, Chaudhuri JB, Mann S, Roach HI, Oreffo RO. Strategies to promote chondrogenesis and osteogenesis from human bone marrow cells and articular chondrocytes encapsulated in polysaccharide templates. Tissue Engineering. 2006;12(10):2789-2799.

24. Pound JC, Green DW, Roach HI, Mann S, Oreffo ROC. An ex vivo model for chondrogenesis and osteogenesis. Biomaterials. 2007;28(18):2839-2849.

25. Ueno H, Yamada H, Tanaka I, Kaba N, Matsuura M, Okumura M, et al. Accelerating effects of chitosan for healing at early phase of experimental open wound in dogs. Biomaterials. 1999;20(15):1407-1414.

26. Ueno H, Mori T, Fujinaga T. Topical formulations and wound healing applications of chitosan. Advanced Drug Delivery Reviews. 2001;52(2):105-115.

27. Hoekstra A, Struszczyk H, Kivekas O. Percutaneous microcrystalline chitosan application for sealing arterial puncture sites. Biomaterials. 1998;19(16):1467-1471.

28. Khor E. Chitin: a biomaterial in waiting. Current Opinion in Solid State \& Materials Science. 2002;6(4):313-317.

29. Lee JY, Nam SH, Im SY, Park YJ, Lee YM, Seol YJ, et al. Enhanced bone formation by controlled growth factor delivery from chitosan-based biomaterials. Journal of Controlled Release. 2002;78(1-3):187-197.

30. Chatelet C, Damour O, Domard A. Influence of the degree of acetylation on some biological properties of chitosan films. Biomaterials. 2001;22(3):261-268.

31. Pangburn SH, Trescony PV, Heller J. Lysozyme degradation of partially deacetylated chitin, its films and hydrogels. Biomaterials. 1982;3(2):105-108.

32. Sashiwa H, Saimoto H, Shigemasa Y, Ogawa R, Tokura S. Lysozyme susceptibility of partially deacetylated chitin. International Journal of Biological Macromolecules. 1990;12(5):295-296.

33. Varum KM, Myhr MM, Hjerde RJ, Smidsrod O. In vitro degradation rates of partially N-acetylated chitosans in human serum. Carbohydrate Research. 1997;299(1-2):99-101.

34. Martins AM, Pham QP, Malafaya PB, Raphael RM, Kasper FK, Reis RL, et al. "Smart" and stimulus responsive chitosan-based scaffolds/cells for bone tissue engineering: influence of lysozyme upon scaffold degradation and osteogenic differentiation of cultured marrow stromal cells induced by CaP coatings. Tissue Engineering Part A. 2008;14(5):795.

35. Martins AM, Santos MI, Azevedo HS, Malafaya PB, Reis RL. Natural origin scaffolds with in situ pore forming capability for bone tissue engineering applications. Acta Biomaterialia. 2008;4(6):1637-1645.

36. Hirano S, Tsuchida H, Nagao N. N-acetylation in chitosan and the rate of its enzymic hydrolysis. Biomaterials. 1989;10(8):574-576.

37. Ma J, Wang H, He B, Chen J. A preliminary in vitro study on the fabrication and tissue engineering applications of a novel chitosan bilayer material as a scaffold of human neofetal dermal fibroblasts. Biomaterials. 2001;22(4):331-336.

38. Brouwer J, van Leeuwen-Herberts T, Otting-van de Ruit M. Determination of lysozyme in serum, urine, cerebrospinal fluid and feces by enzyme immunoassay. Clinica Chimica Acta; International Journal of Clinical Chemistry. 1984;142(1):21-30.

39. Hankiewicz J, Swierczek E. Lysozyme in human body fluids. Clinica Chimica Acta; International Journal of Clinical Chemistry. 1974;57(3):205-209. 


\section{Toward Osteogenic Differentiation of Marrow Stromal Cells and In Vitro Production}

40. Teijón C, Olmo R, Dolores Blanco M, Romero A, María Teijón J. Effects of lead administration at low doses 625 by different routes on rat spleens. Study of response of splenic lymphocytes and tissue lysozyme. Toxicology. 626 $2003 ; 191(2-3): 245-258$.

41. Torsteinsdottir I, Hakansson L, Hallgren R, Gudbjornsson B, Arvidson NG, Venge P. Serum lysozyme: a poten- 628 tial marker of monocyte/macrophage activity in rheumatoid arthritis. Rheumatology (Oxford, England). 629 1999;38(12):1249-1254.

42. Garcia Cruz DM, Escobar Ivirico JL, Gomes MM, Gomez Ribelles JL, Sanchez MS, Reis RL, et al. Chitosan microparticles as injectable scaffolds for tissue engineering. Journal of Tissue Engineering and Regenerative Medicine. 2008;2(6):378-380.

43. Abarrategi A, Civantos A, Ramos V, Sanz Casado JV, Lopez-Lacomba JL. Chitosan film as rhBMP2 carrier: delivery properties for bone tissue application. Biomacromolecules. 2008;9(2):711-718.

44. Park YJ, Lee YM, Park SN, Sheen SY, Chung CP, Lee SJ. Platelet derived growth factor releasing chitosan sponge for periodontal bone regeneration. Biomaterials. 2000;21(2):153-159.

45. Di Martino A, Sittinger M, Risbud MV. Chitosan: a versatile biopolymer for orthopaedic tissue-engineering. Biomaterials. 2005;26(30):5983-5990.

46. Tuzlakoglu K, Alves CM, Mano JF, Reis RL. Production and characterization of chitosan fibers and 3-D fiber mesh scaffolds for tissue engineering applications. Macromolecular Bioscience. 2004;4(8):811-819.

47. Coutinho DF, Pashkuleva IH, Alves CM, Marques AP, Neves NM, Reis RL. The effect of chitosan on the in vitro biological performance of chitosan-poly(butylene succinate) blends. Biomacromolecules. 2008;9(4): $1139-1145$.

48. Costa-Pinto AR, Salgado AJ, Correlo VM, Sol P, Bhattacharya M, Charbord P, et al Adhesion, proliferation, 645 and osteogenic differentiation of a mouse mesenchymal stem cell line (BMC9) seeded on novel melt-based 646 chitosan/polyester 3D porous scaffolds. Tissue Engineering Part A. 2008;14(6):1049-1057.

49. Malafaya PB, Silva GA, Reis RL. Natural-origin polymers as carriers and scaffolds for biomolecules and cell 648 delivery in tissue engineering applications. Advanced Drug Delivery Reviews. 2007;59(4-5):207-233. 1994;11(4):271-277.

51. Bastioli C, Cerutti A, Guanella I, Romano GC, Tosin M. Physical state and biodegradation behavior of starchpolycaprolactone systems. Journal of Environmental Polymer Degradation. 1995;3(2):81-95.

52. Villar MA, Thomas EL, Armstrong RC. Rheological properties of thermoplastic starch and starch poly(ethyleneco-vinyl alcohol) blends. Polymer. 1995;36(9):1869-1876.

53. Kotnis MA, Obrien GS, Willett JL. Processing and mechanical-properties of biodegradable poly(hydroxybutyrateco-valerate)-starch compositions. Journal of Environmental Polymer Degradation. 1995;3(2):97-105.

54. Mayer JM, Elion GR, Buchanan CM, Sullivan BK, Pratt SD, Kaplan DL. Biodegradable blends of celluloseacetate and starch - Production and properties. Journal of Macromolecular Science. Pure and Applied Chemistry. 1995;A32(4):775-785.

55. Nakamatsu J, Torres FG, Troncoso OP, Min-Lin Y, Boccaccini AR. Processing and characterization of porous structures from chitosan and starch for tissue engineering scaffolds. Biomacromolecules. 2006;7(12): 3345-3355.

56. Bajpai AK, Shrivastava J. alpha-Amylase induced enhanced enzymatic degradation of binary polymeric blends of crosslinked starch and gelatin. Journal of Macromolecular Science. Pure and Applied Chemistry. 2004; A41(8):949-969.

57. Gomes ME, Ribeiro AS, Malafaya PB, Reis RL, Cunha AM. A new approach based on injection moulding to produce biodegradable starch-based polymeric scaffolds: morphology, mechanical and degradation behaviour. Biomaterials. 2001;22(9):883-889.

58. Malafaya PB, Elvira C, Gallardo A, San Roman J, Reis RL. Porous starch-based drug delivery systems proc- 670 essed by a microwave route. Journal of Biomaterials Science. 2001;12(11):1227-1241.

59. Elvira C, Mano JF, San Roman J, Reis RL. Starch-based biodegradable hydrogels with potential biomedical 672 applications as drug delivery systems. Biomaterials. 2002;23(9):1955-1966.

60. Espigares I, Elvira C, Mano JF, Vazquez B, San RJ, Reis RL. New partially degradable and bioactive acrylic 674 bone cements based on starch blends and ceramic fillers. Biomaterials. 2002;23(8):1883-1895. 675

61. Leonor IB, Sousa RA, Cunha AM, Reis RL, Zhong ZP, Greenspan D. Novel starch thermoplastic/bioglass 676 composites: mechanical properties, degradation behavior and in-vitro bioactivity. Journal of Materials Science. 677 2002;13(10):939-945.

62. Baran ET, Mano JF, Reis RL Starch-chitosan hydrogels prepared by reductive alkylation cross-linking. Journal 679 of Materials Science. 2004;15(7):759-765. 


\section{A. M. Martins et al.}

63. Boesel LF, Fernandes MH, Reis RL. The behavior of novel hydrophilic composite bone cements in simulated body fluids. Journal of Biomedical Materials Research. Part B Applied Biomaterials. 2004;70(2):368-377.

64. Salgado AJ, Coutinho OP, Reis RL. Novel starch-based scaffolds for bone tissue engineering: cytotoxicity, cell culture, and protein expression. Tissue Engineering. 2004;10(3-4):465-474.

65. Oliveira AL, Reis RL. Pre-mineralisation of starch/polycrapolactone bone tissue engineering scaffolds by a calcium-silicate-based process. Journal of Materials Science. 2004;15(4):533-540.

66. Pavlov MP, Mano JF, Neves NM, Reis RL. Fibers and 3D mesh scaffolds from biodegradable starch-based blends: production and characterization. Macromolecular Bioscience. 2004;4(8):776-784.

67. Tuzlakoglu K, Bolgen N, Salgado AJ, Gomes ME, Piskin E, Reis RL. Nano- and micro-fiber combined scaffolds: a new architecture for bone tissue engineering. Journal of Materials Science. 2005;16(12):1099-1104.

68. Malafaya PB, Stappers F, Reis RL. Starch-based microspheres produced by emulsion crosslinking with a potential media dependent responsive behavior to be used as drug delivery carriers. Journal of Materials Science. 2006;17(4):371-377.

69. Silva GA, Coutinho OP, Ducheyne P, Shapiro IM, Reis RL. Starch-based microparticles as vehicles for the delivery of active platelet-derived growth factor. Tissue Engineering. 2007;13(6):1259-1268.

70. Gomes ME, Azevedo HS, Moreira AR, Ella V, Kellomaki M, Reis RL. Starch-poly(epsilon-caprolactone) and starch-poly(lactic acid) fibre-mesh scaffolds for bone tissue engineering applications: structure, mechanical properties and degradation behaviour. Journal of Tissue Engineering and Regenerative Medicine. 2008;2(5):243-252.

71. Azevedo HS, Gama FM, Reis RL. In vitro assessment of the enzymatic degradation of several starch based biomaterials. Biomacromolecules. 2003;4(6):1703-1712.

72. Balmayor ER, Tuzlakoglu K, Marques AP, Azevedo HS, Reis RL. A novel enzymatically-mediated drug delivery carrier for bone tissue engineering applications: combining biodegradable starch-based microparticles and differentiation agents. Journal of Materials Science. 2008;19(4):1617-1623.

73. Mendes SC, Reis RL, Bovell YP, Cunha AM, van Blitterswijk CA, de Bruijn JD. Biocompatibility testing of novel starch-based materials with potential application in orthopaedic surgery: a preliminary study. Biomaterials. 2001;22(14):2057-2064.

74. Marques AP, Reis RL, Hunt JA. The biocompatibility of novel starch-based polymers and composites: in vitro studies. Biomaterials. 2002;23(6):1471-1478.

75. Salgado AJ, Coutinho OP, Reis RL, Davies JE. In vivo response to starch-based scaffolds designed for bone tissue engineering applications. Journal of Biomedical Materials Research. 2007;80(4):983-989.

76. Martins AM, Pham QP, Malafaya PB, Sousa RA, Gomes ME, Raphael RM, et al. The role of lipase and $\alpha$-amylase in both the degradation of starch/poly( $\varepsilon$-caprolactone) fiber meshes and the osteogenic differentiation of cultured marrow stromal cells. Tissue Engineering Part A. 2009;15(2):295-305.

77. Gu F, Amsden B, Neufeld R. Sustained delivery of vascular endothelial growth factor with alginate beads. Journal of Controlled Release. 2004;96(3):463-472.

78. Shapiro L, Cohen S. Novel alginate sponges for cell culture and transplantation. Biomaterials. 1997;18(8): 583-590.

79. Augst AD, Kong HJ, Mooney DJ. Alginate hydrogels as biomaterials. Macromolecular Bioscience. 2006;6(8): 623-633.

80. Orive G, Hernandez RM, Gascon AR, Calafiore R, Chang TM, de Vos P, et al. Cell encapsulation: promise and progress. Nature Medicine. 2003;9(1):104-107.

81. Alsberg E, Anderson KW, Albeiruti A, Rowley JA, Mooney DJ. Engineering growing tissues. Proceedings of the National Academy of Sciences of the United States of America. 2002;99(19):12025-12030.

82. Wong M. Alginates in tissue engineering. Methods in Molecular Biology (Clifton, NJ). 2004;238:77-86.

83. Hou T, Xu J, Li Q, Feng J, Zen L. In vitro evaluation of a fibrin gel antibiotic delivery system containing mesenchymal stem cells and vancomycin alginate beads for treating bone infections and facilitating bone formation. Tissue Engineering Part A. 2008;14(7):1173-1182.

84. Cai X, Lin Y, Ou G, Luo E, Man Y, Yuan Q, et al. Ectopic osteogenesis and chondrogenesis of bone marrow stromal stem cells in alginate system. Cell Biology International. 2007;31(8):776-783.

85. Barralet JE, Wang L, Lawson M, Triffitt JT, Cooper PR, Shelton RM. Comparison of bone marrow cell growth on 2D and 3D alginate hydrogels. Journal of Materials Science. 2005;16(6):515-519.

86. Barrere F, van Blitterswijk CA, de Groot K. Bone regeneration: molecular and cellular interactions with calcium phosphate ceramics. International Journal Of Nanomedicine. 2006;1(3):317-332.

87. den Hollander W, Patka P, Klein CP, Heidendal GA. Macroporous calcium phosphate ceramics for bone substitution: a tracer study on biodegradation with 45Ca tracer. Biomaterials. 1991;12(6):569-573.

88. Lu J, Descamps M, Dejou J, Koubi G, Hardouin P, Lemaitre J, et al. The biodegradation mechanism of calcium phosphate biomaterials in bone. Journal of Biomedical Materials Research. 2002;63(4):408-412. 


\section{Toward Osteogenic Differentiation of Marrow Stromal Cells and In Vitro Production}

89. Wenisch S, Stahl JP, Horas U, Heiss C, Kilian O, Trinkaus K, et al. In vivo mechanisms of hydroxyapatite 739 ceramic degradation by osteoclasts: fine structural microscopy. Journal of Biomedical Materials Research. 740 2003;67(3):713-718.

90. Zerbo IR, Bronckers AL, de Lange G, Burger EH. Localisation of osteogenic and osteoclastic cells in porous 742 beta-tricalcium phosphate particles used for human maxillary sinus floor elevation. Biomaterials. 743 2005;26(12):1445-1451

91. Hench LL, Splinter RJ, Allen WC, Greenee TK. Bonding mechanisms at the inetrface of ceramics prosthetic 745 materials. Journal of Biomedical Materials Research. 1972;2:117-141.

92. Abe Y, Kokubo T, Yamamuro T. Apatite coating on ceramics, metals and polymers utilizing a biological proc- 747 ess. Journal of Materials Science. Materials in Medicine. 1990;1(4):233-238. 748

93. Kokubo T. Bioactive glass ceramics: properties and applications. Biomaterials. 1991;12(2):155-163. 749

94. Ohtsuki C, Kamitakahara M, Miyazaki T. Coating bone-like apatite onto organic substrates using solutions 750 mimicking body fluid. Journal of Tissue Engineering And Regenerative Medicine. 2007;1(1):33-38. $\quad 751$

95. Reis RL, Cunha AM, Fernandes MH, Correia RN. Treatments to induce the nucleation and growth of apatite- 752 like layers on polymeric surfaces and foams. Journal of Materials Science. 1997;8(12):897-905. 753

96. Martins AM, Salgado AJ, Azevedo HS, Leonor IB, Reis RL. Lysozyme incorporation in biomimetic coated 754 chitosan scaffolds: development and behaviour in contact with osteoblastic-like cells. Tissue Engineering. 755 2006;12(4):1018-1019.

97. Tuzlakoglu K, Reis RL. Formation of bone-like apatite layer on chitosan fiber mesh scaffolds by a biomimetic 757 spraying process. Journal of Materials Science. 2007;18(7):1279-1286. scaffolds/cells for bone tissue engineering: influence of lysozyme upon scaffold degradation and osteogenic 760 differentiation of cultured marrow stromal cells induced by CaP coatings. Tissue Engineering Part A, in press. 761

99. Liu Y, Hunziker EB, Layrolle P, de Bruijn JD, de Groot K. Bone morphogenetic protein 2 incorporated into 762 biomimetic coatings retains its biological activity. Tissue Engineering. 2004;10(1-2):101-108. 763

100. Liu Y, Hunziker EB, Randall NX, de Groot K, Layrolle P. Proteins incorporated into biomimetically prepared 764 calcium phosphate coatings modulate their mechanical strength and dissolution rate. Biomaterials. 765 2003;24(1):65-70.

101. Azevedo HS, Leonor IB, Alves CM, Reis RL. Incorporation of proteins and enzymes at different stages of the 767 preparation of calcium phosphate coatings on a degradable substrate by a biomimetic methodology. Materials 768 Science \& Engineering C. Biomimetic and Supramolecular Systems. 2005;25(2):169-179.

102. Cornell CN. Osteoconductive materials and their role as substitutes for autogenous bone grafts. Orthopedic 770 Clinics of North America. 1999;30(4):591-598.

103. Albrektson T, Johanson C. Osteoni 2001;10(Suppl 2):S96-S101.

104. Fujibayashi S, Neo M, Kim HM, Kokubo T, Nakamura T. Osteoinduction of porous bioactive titanium metal. 774 Biomaterials. 2004;25(3):443-450

105. Ripamonti U. Osteoinduction in porous hydroxyapatite implanted in heterotopic sites of different animal 776 models. Biomaterials. 1996;17(1):31-35.

106. Yuan H, Li Y, de Bruijn JD, de Groot K, Zhang X. Tissue responses of calcium phosphate cement: a study in 778 dogs. Biomaterials. 2000;21(12):1283-1290.

107. Habibovic P, de Groot K. Osteoinductive biome Tissue Engineering and Regenerative Medicine. 2007;1(1):25-32. of octacalcium phosphate coatings applied on porous metal implants. Journal of Biomedical Materials 783 Research. 2003;66(4):779-788. coatings. Annals of Biomedical Engineering. 2004;32(3):398-406.

110. Liu Y, Li JP, Hunziker EB, de Groot K. Incorporation of growth factors into medical devices via biomimetic 787 coatings. Philosophical Transactions. Series A. Mathematical, Physical, and Engineering Sciences. 788 2006;364(1838):233-248.

111. El-Ghannam A. Bone reconstruction: from bioceramics to tissue engineering. Expert Review of Medical 790 Devices. 2005;2(1 doi:10.1586/17434440.2.1.87):87-101.

112. Paul W, Sharma CP. Ceramic drug delivery: a perspective. Journal of Biomaterials Applications. 792 2003;17(4):253-264.

113. LeGeros RZ. Properties of osteoconductive biomaterials: calcium phosphates. Clinical Orthopaedics and 794 Related Research. 2002 (395):81-98. 


\section{A. M. Martins et al.}

114. Vroman L, Adams AL. Rapid identification of proteins on flat surfaces, using antibody-coated metal oxide suspensions. Journal of Immunological Methods. 1986;93(2):213-216.

115. Maus U, Andereya S, Gravius S, Ohnsorge JA, Niedhart C, Siebert CH. BMP-2 incorporated in a tricalcium phosphate bone substitute enhances bone remodeling in sheep. Journal of Biomaterials Applications. 2008;22(6):559-576.

116. Liu Y, de Groot K, Hunziker EB. BMP-2 liberated from biomimetic implant coatings induces and sustains direct ossification in an ectopic rat model. Bone. 2005;36(5):745-757.

117. Ripamonti U, Yeates L, van den Heever B. Initiation of heterotopic osteogenesis in primates after chromatographic adsorption of osteogenin, a bone morphogenetic protein, onto porous hydroxyapatite. Biochemical and Biophysical Research Communications. 1993;193(2):509-517.

118. Onuma K, Kanzaki N, Kobayashi N. Association of calcium phosphate and fibroblast growth factor-2: a dynamic light scattering study. Macromolecular Bioscience. 2004;4(1):39-46.

119. Liu Y, Layrolle P, de Bruijn J, van Blitterswijk C, de Groot K. Biomimetic coprecipitation of calcium phosphate and bovine serum albumin on titanium alloy. Journal of Biomedical Materials Research. 2001;57(3):327-335.

120. Wen HB, de Wijn JR, van Blitterswijk CA, de Groot K. Incorporation of bovine serum albumin in calcium phosphate coating on titanium. Journal of Biomedical Materials Research. 1999;46(2):245-252.

121. Radin S, Campbell JT, Ducheyne P, Cuckler JM. Calcium phosphate ceramic coatings as carriers of vancomycin. Biomaterials. 1997;18(11):777-782.

122. de Groot K, Geesink R, Klein CP, Serekian P. Plasma sprayed coatings of hydroxylapatite. Journal of Biomedical Materials Research. 1987;21(12):1375-1381.

123. Liu Y, Enggist L, Kuffer AF, Buser D, Hunziker EB. The influence of BMP-2 and its mode of delivery on the osteoconductivity of implant surfaces during the early phase of osseointegration. Biomaterials. 2007;28(16): 2677-2686.

124. Klein CP, Patka P, Wolke JG, de Blieck-Hogervorst JM, de Groot K. Long-term in vivo study of plasmasprayed coatings on titanium alloys of tetracalcium phosphate, hydroxyapatite and alpha-tricalcium phosphate. Biomaterials. 1994;15(2):146-150.

125. Liu Y, Huse RO, de Groot K, Buser D, Hunziker EB. Delivery mode and efficacy of BMP-2 in association with implants. Journal of Dental Research. 2007;86(1):84-89.

126. Krebsbach PH, Kuznetsov SA, Bianco P, Robey PG. Bone marrow stromal cells: characterization and clinical application. Critical Reviews in Oral Biology and Medicine. 1999;10(2):165-181.

127. Friedenstein AJ. Precursor cells of mechanocytes. International Review of Cytology. 1976;47:327-359.

128. Friedenstein AJ. Marrow stromal fibroblasts. Calcified Tissue International. 1995;56(Suppl 1):S17.

129. Owen M, Friedenstein AJ. Stromal stem cells: marrow-derived osteogenic precursors. Ciba Foundation Symposium. 1988;136:42-60.

130. Caplan AI. Mesenchymal stem cells. Journal of Orthopaedic Research. 1991;9(5):641-650.

131. Caplan AI. Review: mesenchymal stem cells: cell-based reconstructive therapy in orthopedics. Tissue Engineering. 2005;11(7-8):1198-1211.

132. Derubeis AR, Cancedda R. Bone marrow stromal cells (BMSCs) in bone engineering: limitations and recent advances. Annals of Biomedical Engineering. 2004;32(1):160-165.

133. Bianco P, Riminucci M, Gronthos S, Robey PG. Bone marrow stromal stem cells: nature, biology, and potential applications. Stem Cells. 2001;19(3):180-192.

134. Bellows CG, Heersche JN, Aubin JE. Determination of the capacity for proliferation and differentiation of osteoprogenitor cells in the presence and absence of dexamethasone. Developmental Biology. 1990;140(1): $132-138$.

135. Liu F, Aubin JE, Malaval L. Expression of leukemia inhibitory factor (LIF)/interleukin-6 family cytokines and receptors during in vitro osteogenesis: differential regulation by dexamethasone and LIF. Bone. 2002;31(1):212-219.

136. Tuan RS, Boland G, Tuli R. Adult mesenchymal stem cells and cell-based tissue engineering. Arthritis Research \& Therapy. 2003;5(1):32-45.

137. Chung CH, Golub EE, Forbes E, Tokuoka T, Shapiro IM. Mechanism of action of beta-glycerophosphate on bone cell mineralization. Calcified Tissue International. 1992;51(4):305-311.

138. Tenenbaum HC, Limeback H, McCulloch CA, Mamujee H, Sukhu B, Torontali M. Osteogenic phase-specific co-regulation of collagen synthesis and mineralization by beta-glycerophosphate in chick periosteal cultures. Bone. 1992;13(2):129-138.

139. Beck GR, Jr., Zerler B, Moran E. Phosphate is a specific signal for induction of osteopontin gene expression. Proceedings of the National Academy of Sciences of the United States of America. 2000;97(15):8352-8357. 


\section{Toward Osteogenic Differentiation of Marrow Stromal Cells and In Vitro Production}

140. Quarles LD, Yohay DA, Lever LW, Caton R, Wenstrup RJ. Distinct proliferative and differentiated stages of 853 murine Mc3t3-E1 cells in culture - An invitro model of osteoblast development. Journal of Bone and Mineral 854 Research. 1992;7(6):683-692.

141. Franceschi RT, Iyer BS, Cui Y. Effects of ascorbic acid on collagen matrix formation and osteoblast differen- 856 tiation in murine MC3T3-E1 cells. Journal of Bone and Mineral Research. 1994;9(6):843-854.

142. Liu P, Oyajobi BO, Russell RG, Scutt A. Regulation of osteogenic differentiation of human bone marrow 858 stromal cells: interaction between transforming growth factor-beta and $1,25(\mathrm{OH})(2)$ vitamin $\mathrm{D}(3)$ in vitro. 859 Calcified Tissue International. 1999;65(2):173-180.

143. Gomes ME, Bossano CM, Johnston CM, Reis RL, Mikos AG. In vitro localization of bone growth factors in 861 constructs of biodegradable scaffolds seeded with marrow stromal cells and cultured in a flow perfusion bio- 862 reactor. Tissue Engineering. 2006;12(1):177-188.

144. Pham QP, Kurtis Kasper F, Scott Baggett L, Raphael RM, Jansen JA, Mikos AG. The influence of an in vitro 864 generated bone-like extracellular matrix on osteoblastic gene expression of marrow stromal cells. Biomaterials. 865 2008;29(18):2729-2739.

145. Owen TA, Aronow M, Shalhoub V, Barone LM, Wilming L, Tassinari MS, et al. Progressive development of 867 the rat osteoblast phenotype in vitro: reciprocal relationships in expression of genes associated with osteoblast 868 proliferation and differentiation during formation of the bone extracellular matrix. Journal of Cellular 869 Physiology. 1990;143(3):420-430.

146. Frost HM. Tetracycline-based histological analysis of bone remodeling. Calcified Tissue Research 871 1969;3(3):211-237. ferentiation of bone marrow stromal cells cultured on starch-based three-dimensional scaffolds. Journal of 874 Biomedical Materials Research. 2003;67(1):87-95.

148. Boskey AL. Biomineralization: conflicts, challenges, and opportunities. Journal of Cellular Biochemistry. 876 Supplementary. 1998;30-31:83-91. on the proliferation Hu, Reis RL, Mikos AG. Influence of the porosity of starch-based fiber mesh scaffolds 878 bioreactor. Tissue Engineering. 2006;12(4):801-809.

150. Holtorf HL, Jansen JA, Mikos AG. Flow perfusion culture induces the osteoblastic differentiation of marrow stroma cell-scaffold constructs in the absence of dexamethasone. Journal of Biomedical Materials Research. 2005;72(3):326-334.

151. Hoshi K, Kemmotsu S, Takeuchi Y, Amizuka N Ozawa H. The primary calcification in bones follows removal 884 of decorin and fusion of collagen fibrils. Journal of Bone and Mineral Research. 1999;14(2):273-280. 885

152. Bianco P, Fisher LW, Young MF, Termine JD, Robey PG. Expression of bone sialoprotein (BSP) in developing 886 human tissues. Calcified Tissue International. 1991;49(6):421-426.

153. Mark MP, Butler WT, Prince CW, Finkelman RD, Ruch JV. Developmental expression of 44-kDa bone phos- 888 phoprotein (osteopontin) and bone gamma-carboxyglutamic acid (Gla)-containing protein (osteocalcin) in 889 calcifying tissues of rat. Differentiation. 1988;37(2):123-136.

154. Bianco P, Riminucci M Silvestrini G, Bonucci E, Termine JD, Fisher LW, et al. Localization of bone sialoprotein (BSP) to Golgi and post-Golgi secretory structures in osteoblasts and to discrete sites in early bone matrix. 892 The Journal of Histochemistry and Cytochemistry. 1993;41(2):193-203.

155. Cancedda R Castagnola P, Cancedda FD, Dozin B, Quarto R. Developmental control of chondrogenesis and 894 osteogenesis. The International Journal of Developmental Biology. 2000;44(6):707-714.

156. Hunter GK, Goldberg HA. Nucleation of hydroxyapatite by bone sialoprotein. Proceedings of the National Academy of Sciences of the United States of America. 1993;90(18):8562-8565.

57. Lian JB, Stein GS. Concepts of osteoblast growth and differentiation: basis for modulation of bone cell devel- 898 opment and tissue formation. Critical Reviews in Oral Biology and Medicine. 1992;3(3):269-305.

158. Lian JB, Stein GS. The developmental stages of osteoblast growth and differentiation exhibit selective 900 responses of genes to growth factors (TGF beta 1) and hormones (vitamin D and glucocorticoids). The Journal 901 of Oral Implantology. 1993;19(2):95-105; discussion 36-37. 


\section{Author Queries}

\section{Chapter No.: $\quad$ CH13}

\begin{tabular}{|c|c|c|}
\hline Queries & Details Required & Author's Response \\
\hline AU1 & $\begin{array}{l}\text { Is the number " } 1 \text { " at the end of this sentence a citation "can be affected by } \\
\text { the porosity of the scaffold l."? If so, please indicate, or if not, please } \\
\text { remove or correct as appropriate. }\end{array}$ & \\
\hline AU2 & $\begin{array}{l}\text { Correct as edited: "molecular weight of chitosan may range from } 300 \text { to } \\
\text { more than } 1,000 \mathrm{kDa} \text { ? }\end{array}$ & \\
\hline AU3 & $\begin{array}{l}\text { Correct as edited: "in some cases, may induce extraskeletal new bone } \\
\text { formation (i.e., they are osteoinductive)."? }\end{array}$ & \\
\hline AU4 & $\begin{array}{l}\text { Correct as written: "namely FGF- } 1 \text { and FGF-2, are produced by oseob- } \\
\text { lasts and are constituents of the bone matrix s"? Is the "s" at the end of the } \\
\text { sentence meant? }\end{array}$ & \\
\hline AU5 & Please provide last page number in Ref. 34 if available. & \\
\hline AU6 & Please update Ref. 98. & \\
\hline
\end{tabular}

